\title{
Rectal lymphoma after colectomy for ulcerative colitis
}

\author{
J P Teare, S M Greenfield, S Slater
}

\begin{abstract}
Primary colonic lymphoma is an increasingly recognised complication of ulcerative colitis. We report the first known case of rectal lymphoma occurring after colectomy and ileorectal anastomosis in ulcerative colitis.
\end{abstract}

Although colonic carcinoma is the major longterm complication of ulcerative colitis, primary colonic lymphoma has also been shown to be associated with ulcerative colitis. Patients present with features similar to carcinoma, with an alteration in bowel habit, passage of blood rectally, or an abdominal/rectal mass. Biopsy of the tumour found at sigmoidoscopy or colonoscopy usually confirms the diagnosis. Surgical excision of lymphoma remains the mainstay of treatment and although chemotherapy or radiotherapy is often given as adjuvant treatment, the value of these treatments cannot be assessed from published reports. We report a patient who presented with a rectal lymphoma many years after ileorectal anastomosis.

\section{Case report}

A 74 year old woman presented in 1956 with severe bloody diarrhoea. At that time sigmoidoscopy showed an acutely inflamed, granular mucosa and a rectal biopsy showed features of an acute proctitis. Repeat stool cultures at presentation were negative. She failed to respond to medical treatment and underwent colectomy (an ileorectal anastomosis was fashioned three months later), having developed toxic megacolon secondary to acute ulcerative colitis. The slides from the original colectomy specimen have been reviewed by Dr Slater and an independent histopathologist, Dr S Rasbridge. These show features typical of ulcerative colitis with pseudopolyp formation, distortion of crypts, crypt abscesses, and a severely inflamed and congested mucosa. In addition, no giant cells, granulomas, or fissuring ulceration were seen and there were no features of ischaemic or pseudomembranous colitis.

During the intervening period she remained well and underwent regular sigmoidoscopy and rectal biopsy. These biopsy specimens merely showed features of chronic and occasionally acute proctitis, but no dysplasia was ever seen (further confirmed by Drs Slater and Rasbridge). This patient was lost to follow up in 1988 but she presented again in August 1990 with a change in bowel habit, passing mucus and blood rectally.

Examination showed a $5 \mathrm{~kg}$ weight loss, no lymphadenopathy, abdominal masses, or organomegaly. At sigmoidoscopy a thickened



Figure 1: Many mitotically active pleomorphic cells infiltrating the rectum.

irregular rectal wall with contact bleeding was found. Biopsy of this showed infiltration and complete replacement of the rectal mucosa by mitotically active pleomorphic cells; these were leucocyte common antigen positive and carcinoembryonic antigen and epithelial membrane antigen negative consistent with a high grade non-Hodgkin's lymphoma (Figs 1 and 2). Further immunocytochemistry confirmed this to be a B cell lymphoma. A small bowel meal showed a narrowed rectum distal to the ileorectal anastomosis, while a chest $x$ ray film, total and differential white cell count, and bone marrow examination were normal. In addition, computed tomography of the thorax failed to show mediastinal lymph nodes.

Since the tumour was found to be fixed in the pelvis at surgery, it was left in situ with the formation of an ileostomy and closure of the rectum; the liver and spleen were normal.

The tumour therefore fulfilled Dawson et al and Richards's criteria for primary colonic lymphoma. ${ }^{2}$ Postoperatively the patient made an uneventful recovery and began combination chemotherapy as an outpatient.

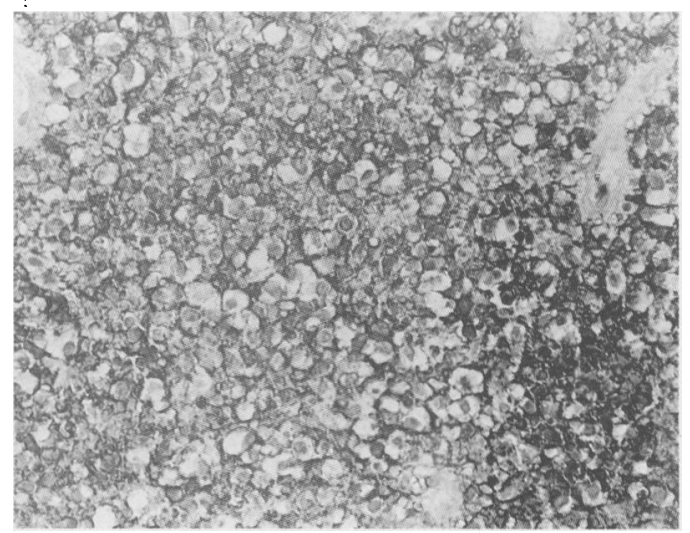

Figure 2: Cell surface membranes of the infiltrating cells stained darkly with leucocyte common antigen. 


\section{Discussion}

Colonic adenocarcinoma is a recognised complication of ulcerative colitis with a $9 \%$ risk at 25 years in an extensive colitis. ${ }^{3}$ Less is known about the association between this disease and primary colonic lymphoma, a rare condition constituting only $0 \cdot 2 \%$ of all colonic malignancies. ${ }^{4}$ There are now approximately 30 reported cases of colonic lymphoma in association with ulcerative colitis. ${ }^{424}$ Eight of these reports described lymphoma involving the rectum. Our patient is unique in that she developed primary lymphoma many years after colectomy and to our knowledge is the first reported case of rectal lymphoma after an ileorectal anastomosis. There has been one report of lymphoma in an ileostomy stoma after colectomy for ulcerative colitis. ${ }^{25}$

The patient we described showed similar features to those patients in one of the largest series of colonic lymphoma in inflammatory bowel disease. ${ }^{26}$ These patients tended to have longstanding colitis, with left sided and often multiple tumours which were B cell, high grade, and at a late stage at diagnosis, being modified Dukes B and C. ${ }^{4}$ An explanation for this delayed presentation is that symptoms may be confused both clinically and radiologically with a disease flare up. ${ }^{27}$ Thus patients with longstanding colitis who notice a change in their symptoms should be thoroughly investigated.

The small numbers of reported cases makes it difficult to prove a definite association between ulcerative colitis and colonic lymphoma, although various mechanisms of pathogenesis have been postulated. These include repeated episodes of lymphoid hyperplasia ${ }^{8}$ and abnormalities of the reticuloendothelial system. ${ }^{10}$

The incidence of carcinoma of the rectum increases with time after an ileorectal anastomosis in ulcerative colitis and tends to occur in those patients with total colonic involvement before surgery. ${ }^{28} \mathrm{We}$ believe our report further emphasises the importance of continued surveillance to detect rectal lymphoma as well as carcinoma.

We thank Dr B Creamer for allowing us to report this patient and acknowledge the help of the histology department at St Thomas's Hospital in preparing photographs of the histology.

1 Dawson IMP, Cornes JS, Morson BC. Primary malignant lymphoid tumours of the intestinal tract. Brf Surg 1961; 49: 80-9.
2 Richards MA. Lymphoma of the colon and rectum. Postgrad Med F 1986; 62: 615-20.

Lennard-Jones JE, Melville DM, Ritchie JK, Williams CB Precancer and cancer in extensive ulcerative colitis: Findings among 401 patients over 22 years. Gut 1990; 31 $800-6$.

4 Shepherd NA, Hall PA, Coates PJ, Levison DA. Primary malignant lymphoma of the colon and rectum. A histopathological and immunohistochemical analysis of 45 cases with clinicopathological correlations. Histopathology 1988; 12: 235-52.

5 Bargen JA. Chronic ulcerative colitis associated with malignant disease. Arch Surg 1928; 17: 561-76.

6 Cattell RB, Boehme EJ. The importance of malignant degeneration as a complication of chronic ulcerative colitis. Gastroenterology 1947; 8: 695-710.

7 Warren KW. Malignant lymphoma of the duodenum, small intestine and colon. Surg Clin North Am 1959; 39: 725-35.

8 Cornes JS, Smith JC, Southwood WFW. Lymphosarcoma in chronic ulcerative colitis. BrF Surg 1961; 49: 50-3.

9 Delannoy E, Buffin RP. Reticulosarcome sur rectocolite haemorragique (colite ulcerative). Presse Med 1962; 70: 1006-7.

10 Sataline LR, Mobley EM, Kirkham W. Ulcerative colitis complicated by colonic lymphoma. Gastroenterology 1963; 44: 342-7.

11 Walker FC, Weaver JPA. Lymphosarcoma in ulcerative colitis. Brf Surg 1964; 51: 475-7.

12 Meadows R. Hodgkin's disease of the colon presenting as disseminated sclerosis with associated ulcerative colitis. Aust disseminated sclerosis with

13 Wychulis AR, Beahrs OH, Woolner LB. Malignant lymphoma of the colon. A study of 69 cases. Arch Surg 1966 63: 215-25.

14 Nugent FW, Zuberi S, Bulon MB, Legg MA. Colonic lymphoma in ulcerative colitis. Lahey Clinic Foundation Bulletin 1972; 21: 104-11.

15 Parikh NK, Shah PM, Patel SM, Chandra DD. Colonic lymphoma in ulcerative colitis. F Assoc Phys India 1973; 21 : 713-6.

16 Renton P, Blackshaw AJ. Colonic lymphoma complicating ulcerative colitis. $B r \mathcal{F}$ Surg 1976; 63: 542-5.

17 Vieta JO, Delgado CE. Chronic ulcerative colitis complicated by colonic lymphoma. Dis Colon Rectum 1976; 19: 56-62.

18 Wagonfield JB, Platz CE, Fishman FL, Sibley RK, Kirsner JB. Multicentric colonic lymphoma complicating ulcerative colitis. Dig Dis Sci 1977; 22: 502-8.

19 Emanuel JCM, Ibister Wh. Chronic mucosal ulcerative colitis with malignant lymphoma: report of a case. Aust NZ $\mathcal{F}$ Surg 1979; 49: 95-8.

20 Bashiti HO, Kraus FT. Histiocytic lymphoma in chronic ulcerative colitis. Cancer 1980; 46: 1695-700.

21 Barki Y, Boult I. Two uncommon malignancies complicating ulcerative colitis. F Can Assoc Radiol 1981; 32: 136-7.

22 Bartolo D, Goepel JR, Parsons MA. Rectal malignant lymphoma in chronic ulcerative colitis. Gut 1982; 23: 164-8.

23 Baker D, Chiprut RO, Rimer D, Lewin KJ, Rosenberg MZ Colonic lymphoma in ulcerative colitis. $\mathcal{F}$ Clin Gastroenterol 1985; 7: 379-86.

24 Hope-Ross M, Magee DJ, O'Donoghue, Murphy JJ. Ulcerative colitis complicated by lymphoma and adenocarcinoma Br F Surg 1985; 72: 22.

25 Lewin KJ, Ranchod M, Dorfman RF. Lymphomas of the gastrointestinal tract. A study of 117 cases presenting with gastrointestinal disease. Cancer 1978; 42: 693.

26 Shepherd NA, Hall PA, Williams GT, et al. Primary malignant lymphoma of the large intestine complicating chronic inflammatory bowel disease. Histopathology $1989 ; 15$ : 325 37.

27 Friedman HB, Silver GM, Brown CH. Lymphoma of the colon simulating ulcerative colitis. Am $\mathcal{F}$ Dig Dis 1968; 13: 910-7.

28 Baker WNW, Glass RE, Ritchie JK, Aylett SO. Cancer of the rectum following colectomy and ileorectal anastomosis for ulcerative colitis. Br $\mathcal{F}$ Surg 1978; 65: 862-8. 